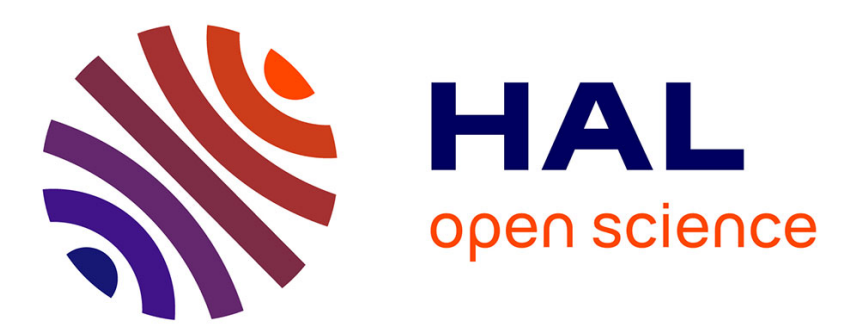

\title{
Investigations on Strain Hardening During Cutting of Heat-Resistant Austenitic Stainless Steel
}

Rabiae Arif, Guillaume Fromentin, Frédéric Rossi, Bertrand Marcon

\section{To cite this version:}

Rabiae Arif, Guillaume Fromentin, Frédéric Rossi, Bertrand Marcon. Investigations on Strain Hardening During Cutting of Heat-Resistant Austenitic Stainless Steel. Journal of Manufacturing Science and Engineering, 2020, 142 (Paper No: MANU-20-1028), pp.051005/1-12. 10.1115/1.4046612 . hal02667940

\section{HAL Id: hal-02667940 \\ https://hal.science/hal-02667940}

Submitted on 31 May 2020

HAL is a multi-disciplinary open access archive for the deposit and dissemination of scientific research documents, whether they are published or not. The documents may come from teaching and research institutions in France or abroad, or from public or private research centers.
L'archive ouverte pluridisciplinaire HAL, est destinée au dépôt et à la diffusion de documents scientifiques de niveau recherche, publiés ou non, émanant des établissements d'enseignement et de recherche français ou étrangers, des laboratoires publics ou privés. 


\author{
Rabiae Arif ${ }^{1}$ \\ Arts et Metiers Institue of Technology, \\ LaBoMaP, UBFC, \\ HESAM Université, \\ Cluny F-71250, France; \\ Saint Jean Tooling, \\ Saint Jean d'Ardières F-69220, France \\ e-mail: rabiae.arif@ensam.eu \\ Guillaume Fromentin \\ Arts et Metiers Institue of Technology, \\ LaBoMaP, UBFC, \\ HESAM Université, \\ Cluny F-71250, France \\ e-mail: guillaume.fromentin@ensam.eu
}

Frédéric Rossi

Arts et Metiers Institue of Technology,

LaBoMaP, UBFC,

HESAM Université,

Cluny F-71250, France

e-mail: frederic.rossi@ensam.eu

\author{
Bertrand Marcon \\ Arts et Metiers Institue of Technology, \\ LaBoMaP, UBFC, \\ HESAM Université, \\ Cluny F-71250, France \\ e-mail: Bertrand.marcon@ensam.eu
}

\section{Investigations on Strain Hardening During Cutting of Heat-Resistant Austenitic Stainless Steel}

This study presents a novel analysis of the machined subsurface layer formation dealing with strain hardening phenomenon which results from complex mechanisms due to cutting edge multiple passes in drilling. On the one hand, the hardened layer during drilling is characterized in relation with the local cutting geometry and thanks to a quick-stop device $(Q S D)$ to suddenly interrupt the operation. Micro hardness is used to determine the hardened thickness of the machined subsurface layers along the local cutting edge geometry. On the other hand, orthogonal cutting performed with a complex self-designed planing experiment is used to investigate in details the hardening accumulation aspects. Then, dedicated methodologies are proposed to quantify the strain hardening as well as the incremental plastic strain generated by consecutive tool passes. In addition to the subsurface hardness evolution, the work material strain is observed during the steady-state cutting process thanks to the high-speed camera. The digital image correlation technique is exploited to analyze not only the plastic strain remaining on the workpiece after the cut but also the effect of the incremental plastic strain generated by the consecutive planing passes as the cutting edges in drilling do. One of the outcomes is that the hardened layer thickness can reach from two to three times the cut thickness in drilling or in planing. As a consequence, this work demonstrates that the cutting process affects itself by hardening. Thus, the studied austenitic stainless steel in such a way that this last is never cut in its initial state.

[DOI: $10.1115 / 1.4046612]$

Keywords: drilling, quick-stop test, strain hardening, digital image correlation, micro hardness, cumulative strain hardened layer, advanced materials and processing, machining processes

\section{Introduction}

In an industrial context, cutting tools' performance is a critical point to enhance productivity in the metal cutting process [1]. Generally, machinability of difficult-to-cut materials like austenitic stainless steel is investigated based on cutting forces evolution. Routio and Säynätjoki have optimized the cutting conditions when drilling austenitic stainless steel in order to enhance the tool life [2]. In the same manner, Sultan et al. also focused their research works on the effect of drilling parameters on both the tool wear and the hole quality in terms of surface roughness and cylindricity [3]. However, from the machinability point of view, the surface integrity of these materials is also a fundamental issue. Dolinšek pointed out that the strain hardening phenomenon is the main surface integrity feature when machining austenitic stainless steels [4]. Furthermore, these alloys are generally considered to have a rather low machinability due to their inherent thermomechanical properties (low conductivity and high mechanical resistance). Additionally, Jiang et al. have shown that the strain hardening phenomenon is also supposed to be responsible for tool wear especially on the rake and flank faces [5]. Although its importance on machinability of austenitic stainless steel, a few investigations have contributed to look for the mechanisms behind strain hardening. Dolinšek demonstrated that the austenite has a high tendency to be plastically deformed due to its compact hexagonal structure which tends to be deformed according to several sliding plans [4]. Hence, Krolczyk et al. show that the increase of hardness and strength are the result of plastic strain

\footnotetext{
${ }^{1}$ Corresponding author.
}

remaining in the machined surface [6]. So far, this last is less studied especially in the case of austenitic stainless steels' machinability.

The strain hardening of the machined surface concerns the surface integrity aspects of the final surface and most of the time the next surface to cut as well. It means that the strain hardening may also affect the cutting process for machining technics which directly recuts the machined surface and even more when it comes to cut with a feed lower than the hardened layer thickness, as it could be in drilling for peculiar material or finishing processes.

For the study of consecutive passes of the cutting edges in the hole bottom during drilling, the only way to assess what occurs with one cutting edge is to suddenly interrupt the drilling operation using a quick-stop device (QSD). Such kind of sudden interrupted machining has been used successfully in turning as in Ref. [7] or planing as in Ref. [8]; few works have been performed in drilling using such equipment. After a literature review, only Dolinšek focuses on the austenitic stainless steel drilling operation and has only analyzed the effect of the cutting conditions (cutting velocity and the feed) on the strain hardening evolution [4].

In the metal cutting investigation, digital image correlation (DIC) is a technique principally used to analyze the chip formation. For instance, Davis et al. have used DIC to characterize the primary shear zone (PSZ) during the chip formation of titanium machining [9]. DIC could be also employed for the identification of constitutive model coefficients during orthogonal cutting as mentioned in Ref. [10]. Recently, the DIC has been also used as an experimental technique to assess the surface integrity of the material subsurface; Baizeau et al. have used DIC to evaluate the deformed layer thickness generated during orthogonal cutting and later with $3 \mathrm{D}$ round cutting tools in planning [11-13]. 
This research work aims to investigate the strain hardening phenomena when machining heat-resistant austenitic stainless steel (HRASS). Indeed, this material may not be cut in its raw state since the hardened layer builtup by the previous pass could be a new harder material to cut partially or entirely depending on its depth and the feed. Thus, the cutting process would be always affected by the strain hardening and resulting in different conditions for the cutting tool.

Firstly, the evolution of strain hardening during the drilling operation is characterized using a self-designed QSD and micro hardness analysis, considering the local cutting geometry at the hole bottom. It should be noticed that the hardened layer observed in drilling results from the cumulative hardening generated by cuts of edges during drilling.

To analyze the cumulative effect of strain hardening generated by each cutting edge pass, further investigations are proposed in orthogonal cutting. Planing tests combined with high-speed imaging and DIC techniques are realized to evaluate the strain

Table 1 Chemical composition of the GX 40 CrNiNbSi 24-12 alloy in wt\% obtained by the spark spectroscopy technique

\begin{tabular}{|c|c|c|c|c|c|c|c|c|c|}
\hline $\mathrm{C}$ & $\mathrm{Co}$ & $\mathrm{Cr}$ & $\mathrm{Ni}$ & $\mathrm{Cu}$ & $\mathrm{Mn}$ & $\mathrm{Si}$ & V & $\mathrm{Nb}$ & W \\
\hline $\begin{array}{l}0.35 \pm \\
0.01\end{array}$ & 0.04 & $\begin{array}{c}24.2 \\
\pm 0.1\end{array}$ & $\begin{array}{l}12 \pm \\
0.04\end{array}$ & 0.04 & 0.34 & 1.8 & 0.12 & $\begin{array}{c}0.5 \pm \\
0.03\end{array}$ & 0.03 \\
\hline
\end{tabular}

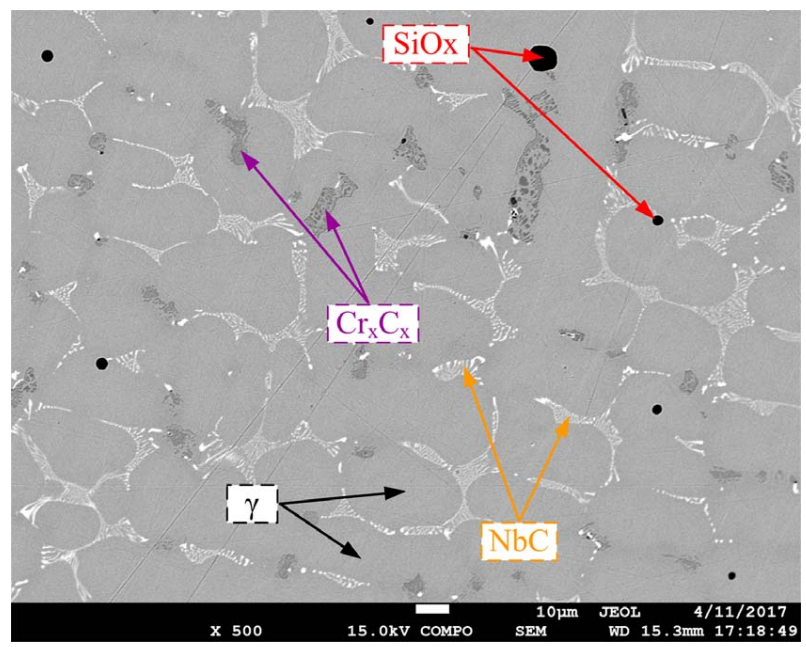

Fig. 1 Microstructure of HRASS obtained by scanning electron microscope (SEM) evolution and its accumulation under successive passes. Then, it is proposed a methodology to identify the incremental plastic strain for each cut.

\section{Investigations on the Drilling Process}

It is well known that the drilling operation is a complex process to study because the chip formation is not easy to observe as well as the machined subsurface on the hole bottom. Moreover, in a standard drilling configuration, it is difficult to interrupt suddenly the cutting process without affecting the hole bottom because of the cutting edges are slowing down, more or less fast, before stopping resulting in a decreasing cutting speed and an important tool friction, possibly for more than a spindle revolution during the axis deceleration. This is the reason why comes the necessity to perform the quick-stop test (QST) to stop instantly the cutting process and hence preserve the workpiece state nearby the cutting edges as close as possible to the actual on cut conditions. The challenge is to get a single tooth passage at the hole bottom to analyze the effect of the cutting conditions on the hardened layer generating by a single cutting edge pass.

2.1 Work Material and Drill Geometry. The work material used in all experiments is GX $40 \mathrm{CrNiNbSi} 24-12$ according to DIN EN 10295 . It contains principally $24 \%$ of chromium and $12 \%$ of nickel with slight traces of silicon and niobium. Table 1 summarizes its nominal composition in weight percentage. That work material is obtained by the casting process without any heat treatment applied. Its heterogeneous microstructure contains an austenitic matrix $\gamma$, very sensitive to strain hardening phenomenon, with austenitic dendrites, hard carbides, and oxides like $\mathrm{NbC}$, $\mathrm{Cr}_{x} C_{x}$, and $\mathrm{SiO}_{x}$ as could be seen in Fig. 1 .

In this section of the work concerning the drilling operation, one AlCrN coated WC-Co twist drill has been used with $5.1 \mathrm{~mm}$ diameter and two teeth $(Z=2)$; Fig. 2 describes the evolution of its rake angle $\gamma_{n}$ and the working clearance angle $\alpha_{f e}$ along the cutting edge. Drills are measured by Alicona Infinite Focus SL focus-variation microscope allowing to measure the rake $\gamma_{n}$ angle in the normal plan $P_{n}$ according to the ISO 3002-2 standard and using a self-developed macro implemented into the CATIA software [14]. Cutting parameters and their levels used in this experimentation are summarized in Table 2 where $V_{c}, f_{z}$, and $h$ are, respectively, the cutting speed, the feed, and the cut thickness. It may be noticed that all drilling experiments are carried out under internal cooling with $8 \%$ water-based emulsion and a pressure of 42 bar and the samples made of GX 40CrNiNbSi 24-12 alloy. HRASS is a $20 \mathrm{~mm}$ diameter by $40 \mathrm{~mm}$ length cylinder.

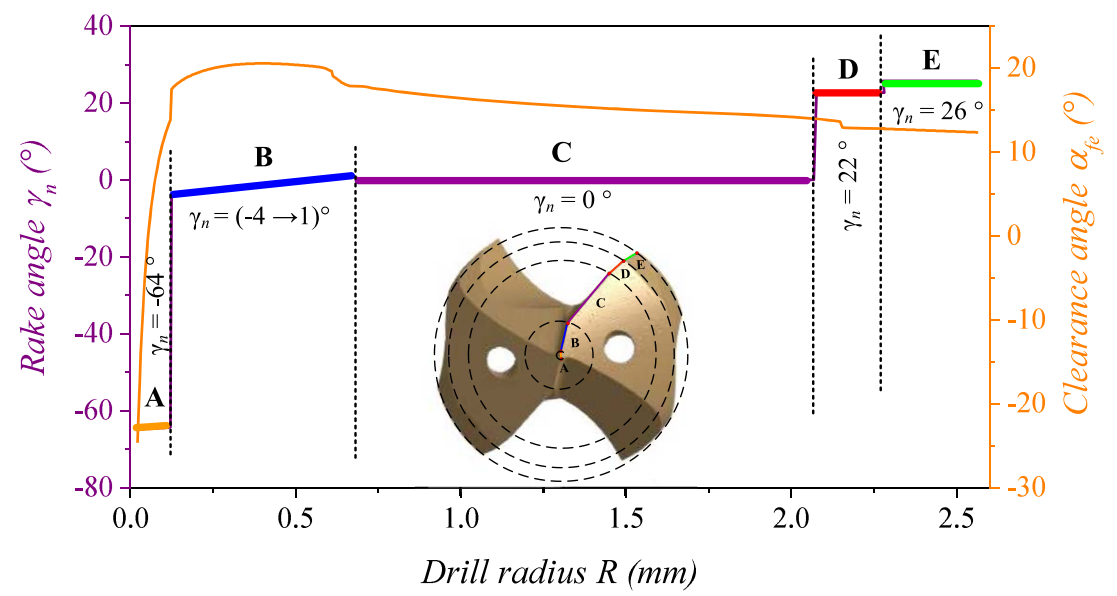

Fig. 2 Evolution of the effective rake angle $\gamma_{n}$ and the working clearance angle $\alpha_{f e}$ along the cutting edge of the twist drill 
Table 2 Cutting parameters used during the quick-stop campaign using the quick-stop device $\left(h=f_{z} \cdot \sin \kappa_{r}\right)$

\begin{tabular}{lcc}
\hline \hline$V_{c}(\mathrm{~m} / \mathrm{min})$ & $f_{z}(\mathrm{~mm} / \mathrm{rev} / \mathrm{th})$ & $h(\mathrm{~mm})$ \\
\hline 10 & 0.025 & 0.023 \\
10 & 0.080 & 0.073 \\
60 & 0.025 & 0.023 \\
60 & 0.080 & 0.073 \\
\hline
\end{tabular}

2.2 Experimental Setting of the Quick-Stop Test. The principle of the QSD in drilling used in this context consists to instantly stop the cutting process during drilling. To do so, the QSD developed by Claudin [15] and later improved by himself is used to block the sample by three jaws actuated by a pneumatic cylinder. The schematic acquisition used is described in Fig. 3. With such a device, the drilling operation runs in a standard configuration.
Once the drill arrives to a defined depth $(5 \mathrm{~mm})$, the device is triggered by computer numerical control (CNC) output causing the immediate jaws opening releasing the sample which starts to spin together with the tool (Fig. 3(c)). The sample is positioned on a mechanical stop, itself mounted on a spring is free to turn and go down with the drill until the programmed $z$ displacement $\left(z_{\text {trig }}\right)$ of the spindle (Figs. 3(b) and 3(c)). In a second time, spindle speed and feed are stopped softly to avoid any sample/tool relative displacement. To be more specific, in this QSD configuration, two requirements should be respected to ensure the accuracy of the work-hardened subsurface layer analysis:

- After its liberation, the acceleration of the workpiece should be very high to rapidly reach the constant spindle speed $\omega_{c}(\sim$ drill speed).

- After triggering, the pneumatic cylinder must react as quickly as possible to perform the instantaneous jaws opening.

(a)

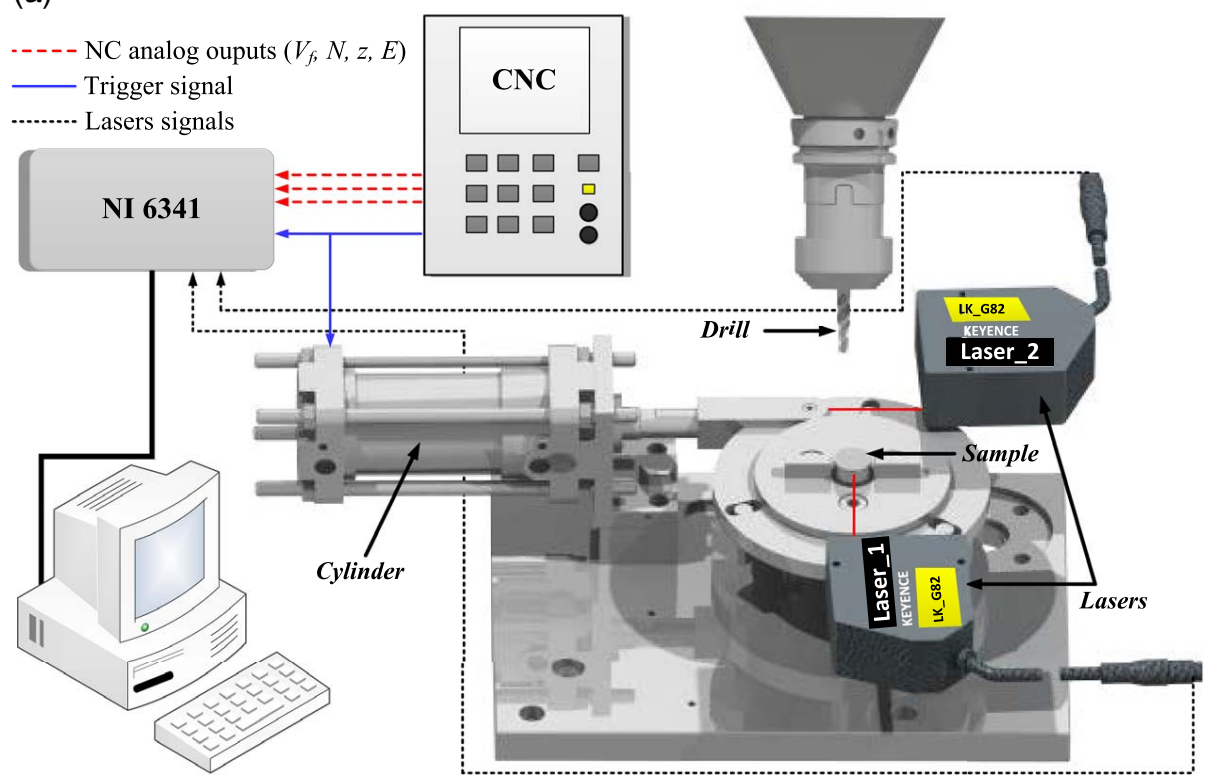

(b)

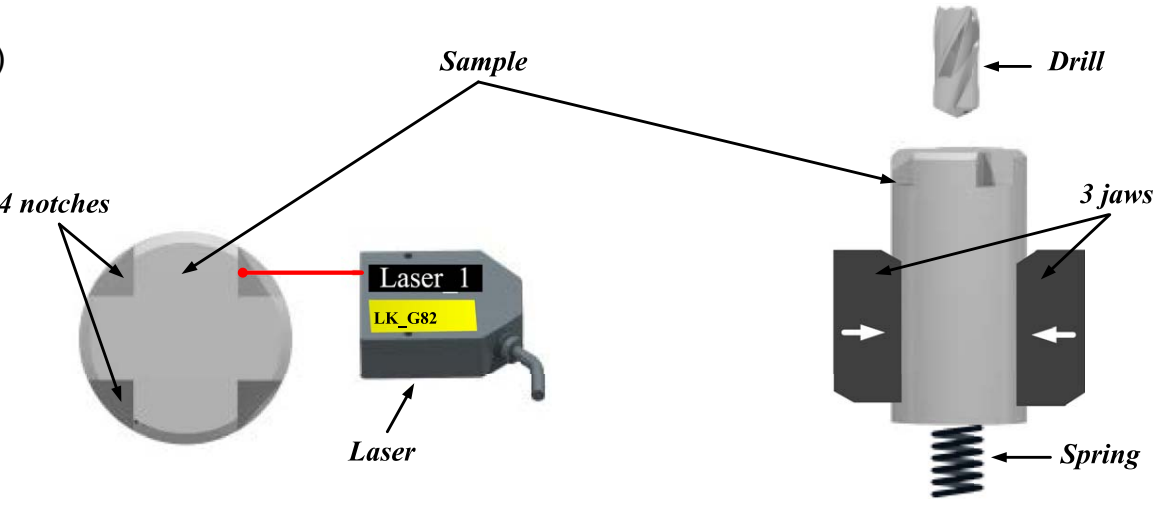

(c)

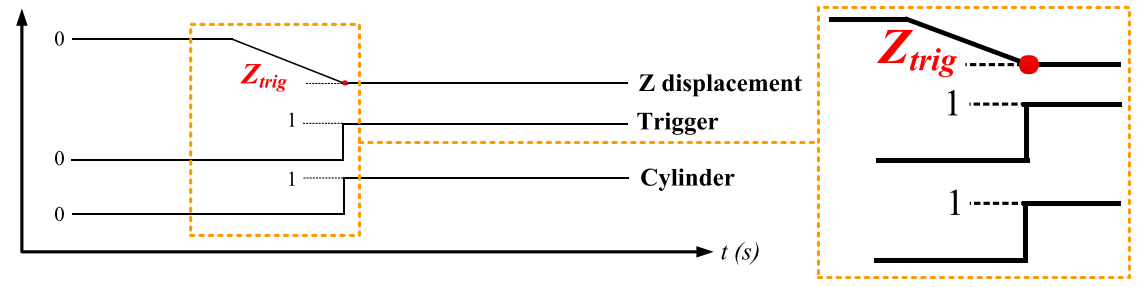

Fig. 3 Acquisition setup for QST 
To assess the QSD performance, some preliminary investigations were necessary. The system requires principally two Keyence triangulation laser sensors type LK G82 allowing measurement at a distance of $80 \pm 2 \mathrm{~mm}$ with a resolution of $1 \mu \mathrm{m}$ and four $\mathrm{CNC}$ analog outputs which are also recorded directly from the machine (feed rate $V_{f}$, spindle speed $N$, tool position $z$, and the angular position of the spindle $E$ ) as described in Fig. 3(a). The first laser measures the cylinder plunger displacement after triggering, while the second is used to compute the angular position of the workpiece after its liberation. To do so, four notches are carved on the side face of the workpieces to measure its rotation during the workpiece acceleration phase, right after the sample releasing, as presented in Fig. 3(b).

During QST, the workpiece kinematic after its liberation is analyzed (Fig. 4). $\delta t$ and $a$, respectively, the acceleration duration and the workpiece acceleration are calculated from the workpiece position recorded by the laser sensors. They, respectively, equal to $2 \mathrm{~ms}$ and $559.10^{4} \mathrm{deg} / \mathrm{s}^{2}$ for $V_{c}=60 \mathrm{~m} / \mathrm{min}$. Additionally, the zone affected by the acceleration phase in the hole bottom has been defined by calculating angle $\theta$ necessary to have the sample rotation speed reaching the spindle one. This is to ensure that the subsequent hardening layer investigation will not be performed in the inadequate workpiece zone generated during the acceleration of the workpiece exhibiting different unsteady cutting conditions. To resume, the QST frees the sample so that it can accelerate from zero to the set spindle speed sweeping $11 \mathrm{deg}$ from the final cutting edge position as described in Fig. 4. Therefore, the workpiece is cut for analyze according to the dashed line, represented in Fig. 4, to analyze the hole bottom surface generated by drill cutting edge without any effect of the cutting relative slowing down.

After QST, the specimens have been prepared for micro hardness tests to analyze the machined subsurfaces. Firstly, they have been surfaced by milling up to the holes axis as shown in Fig. 4. Afterwards, the different specimens have been polished to remove the hardened layer generated during that surfacing. Finally, to ensure that the affected layer by milling is removed and the treated surface is not affected by the polishing process, the surface hardness value is checked far from the drilled surface and compared with the hardness of the bulk material (240$\left.270 \mathrm{HV}_{0.05}\right)$.
2.3 Characterization of the Hardened Layer by Micro Hardness. In this study, filiations of micro hardness have been chosen as a main technique to deal with hardened layer depth. All analysis tests have been carried out on the Wilson ${ }^{\circledR}$ Tukon $^{\text {TM }}$ micro hardness tester. The Knoop indenter form allows measurements closer to the subsurface boundary than the other kind of hardness indenters; this choice has been made to enhance the accuracy of the hardened layer depth determination. A low load is used (50 g) to reduce the impact of an eventual hard carbide located under the observed surface which could disrupt the analysis by providing hardness not corresponding to the bulk material but rather carbide inclusions ones. For the same reason, the micro hardness points are taken only in the austenitic phase $\gamma$ (Fig. 1). In addition, at the least three filiations are achieved at different hole diameters, for each cutting edge identified in Fig. 2, in the hole bottom to link the hardening to the local cutting edge geometry, then their average values are fitted by the one-phase exponential decay function presented by continuous or dashed curves for each analyzed zone. Finally, the depth of the hardened layers is determined by a threshold calculated at $105 \%$ of the asymptote (corresponding to the bulk material) of each curve as shown in Fig. 5(a).

2.3.1 Effect of Cutting Conditions. To study the influence of cutting conditions, only strain hardening generated by one cutting edge segment (segment C) is analyzed. However, later strain hardening evolution is analyzed along the cutting edge. The effect of the feed and the cutting speed on the hardness, the hardened affected layer depth, and their profiles are measured and, respectively, displayed in Figs. 5 and 6. Figure 5 shows the evolution of the Knoop micro hardness as a function of the depth from the hole bottom to the specimens' core for two levels of the feed $f_{z}$, while Fig. 6 displays the effect of $V_{c}$ on the thickness of the hardened layer generated. One can observe on both figures that high cutting conditions tend to increase significantly the hardness of the sublayer and generate a large depth of strain hardening. Particularly, the hardness right under the generated layer increases by $14 \%$ and the depth of the hardened layer by $21 \%$ both when the feed increases from 0.025 to $0.080 \mathrm{~mm} / \mathrm{rev} / \mathrm{th}$. The same trend has been found for the cutting speed $V_{c}$ effect (Fig. 6). Passing from the cutting speed from 10 to $60 \mathrm{~m} / \mathrm{min}$ increases the hardness by $16 \%$, and in the same way by $41 \%$ the thickness of the generated hardened layer.

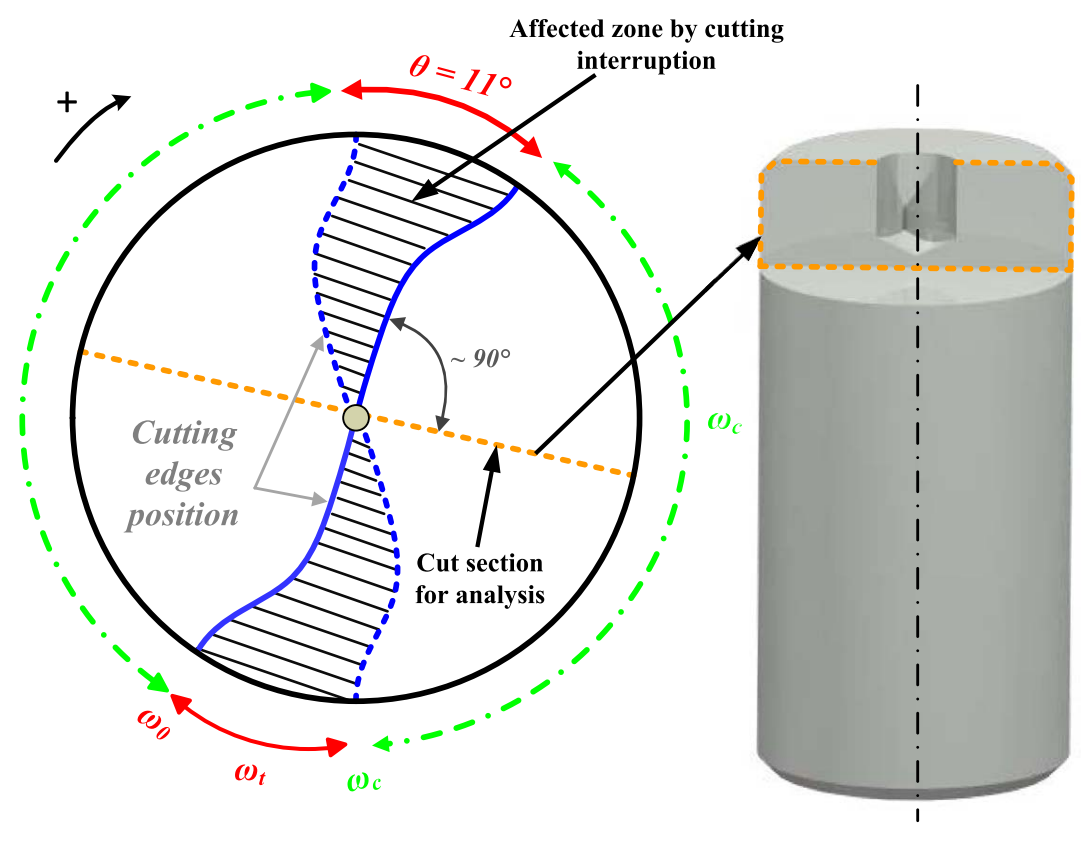

Fig. 4 Scheme of the hole bottom zones affected by the cutting slowing down inside the workpiece after its releasing and definition of the suitable plan to analyze the strain hardening of the work material at the real cutting conditions 

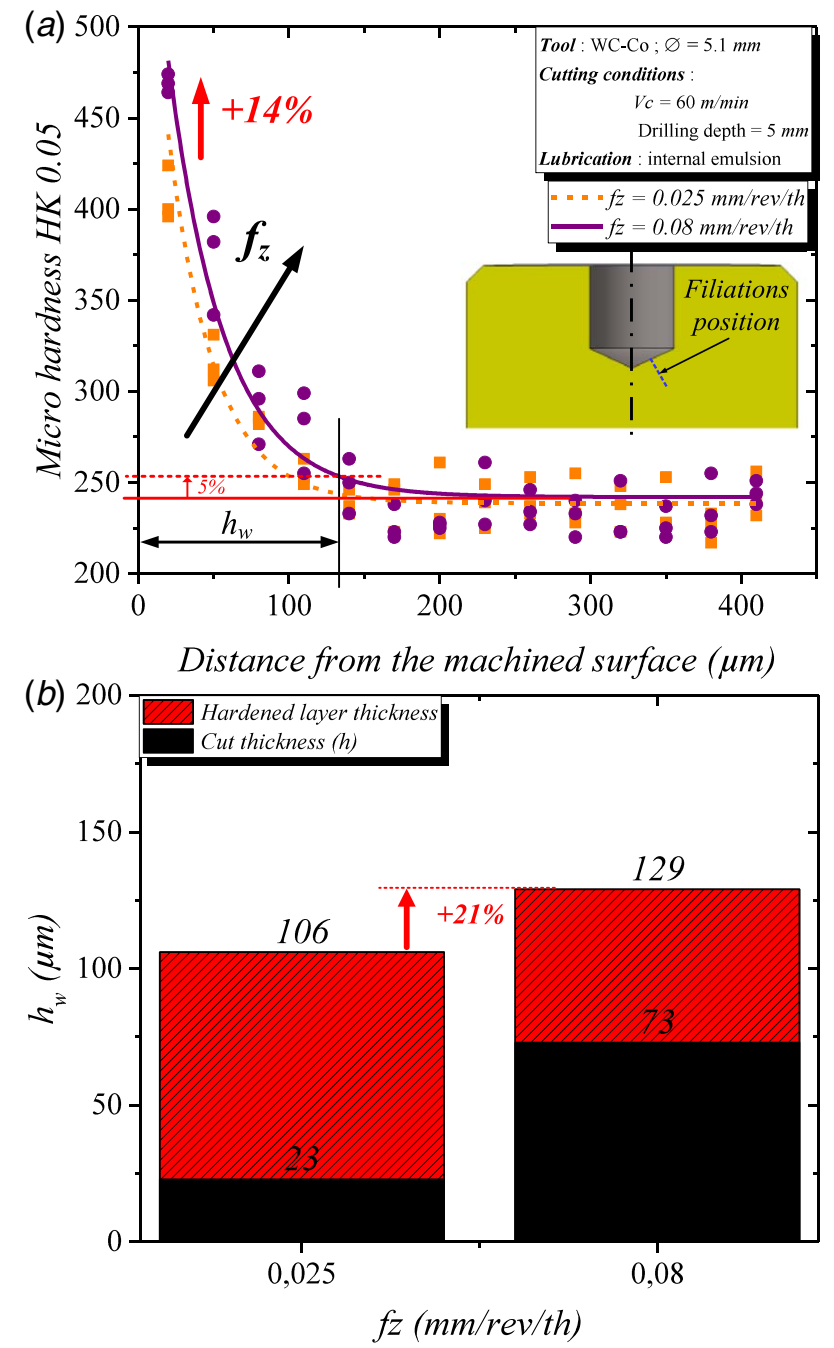

Fig. 5 Effect of the feed $f_{z}$ on (a) the evolution of subsurface hardness and $(b)$ the evolution of hardened layer thickness, for $V_{c}=60 \mathrm{~m} / \mathrm{min}$ and for the surface generated by the edge $C$

In fact, it is well known that metal cutting is constantly accompanied with large plastic deformation occurring in the workpiece material. Referring to the results in Figs. 5(b) and 6(b), the generated strain hardened layer thickness $h_{w}$ can reach two or three times the cut thickness $h$. This shows that during drilling of the studied work material, the cutting edges permanently cut the strain hardened layer remnants from the previous cut.

2.3.2 Effect of the Local Cutting Geometry. The effect of the local cutting geometry, namely the rake angle $\gamma_{n}$, on the strain hardened layer evolution has been also studied considering five regions along the cutting edge as described in Fig. 7; those regions are the same ones than in Fig. 2. Three filiations (marks) have been realized for the five regions allowing to compute the averaged curve presented by the continuous lines. The evolution of the strain hardening developed by each region is presented in Fig. 7(a), while the thickness $h_{w}$ of the strain hardened subsurface layer is presented in Fig. 7(b).

Due to the chamfer at the drill corner, the cut thickness $h$ at the edge $\mathrm{E}$ is different compared to the cut thicknesses view by the other elementary cutting edges. Therefore, the comparison of the hardened layer thickness is made between cutting edges having the same cut thickness $h$ such as the edge D for example. According to Fig. 7, it is observed that the rake angle $\gamma_{n}$, combined with the clearance angle $\alpha_{f e}$, has a significant effect on the strain hardened layer thickness since the hardened layer depth increases by $91 \%$ from the

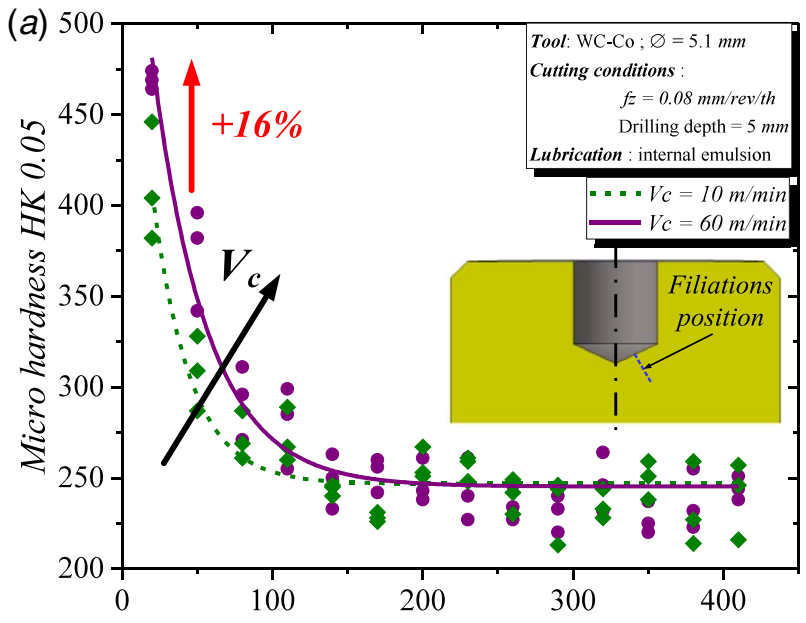

Distance from the machined surface $(\mu \mathrm{m})$

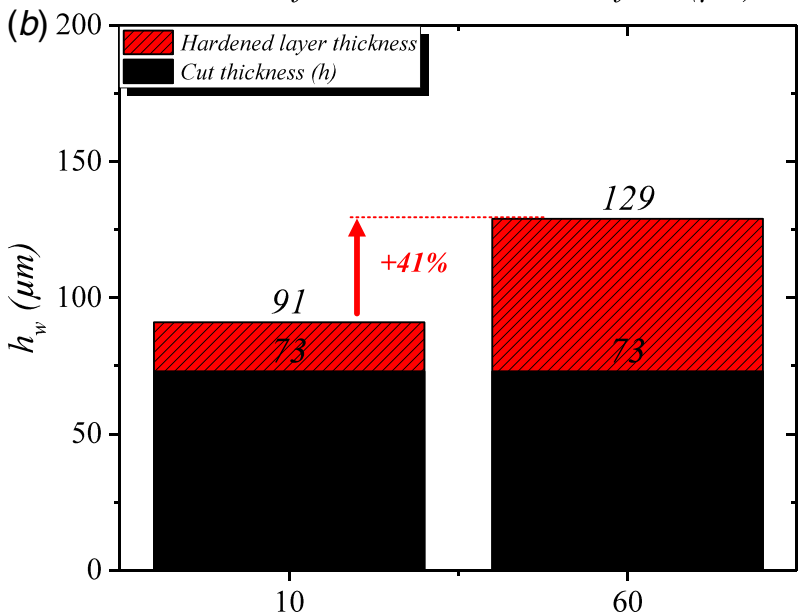

$V c(\mathrm{~m} / \mathrm{min})$

Fig. 6 Effect of cutting speed $V_{c}$ on (a) the evolution of subsurface hardness and $(b)$ the evolution of hardened layer thickness $f z=0.08 \mathrm{~mm} / \mathrm{rev} / \mathrm{th}$ and for the surface generated by the edge C

drill center to the edge D. In fact, the chisel edge (A) generates a larger hardened layer $(202 \mu \mathrm{m})$ compared to edge $\mathrm{D}$ which generates a hardened layer of $106 \mu \mathrm{m}$. This trend could be attributed to the effect of the negative rake angle since the cutting geometry contains edges with high negative rake angle at the drill center ( $\sim 64 \mathrm{deg})$ as displayed in Fig. 2. In addition to negative working clearance angle $\alpha_{f e}$ on the drill web (cf. Fig. 2), this negative rake angle induces a high compressive strain state favorable to cause ploughing and therefore creating a large plastic deformation at the drill center. As mentioned previously, results shown in Fig. 7(b) also display that the strain hardened layer $h_{w}$ generated by the different elementary edges is larger than the cut thickness $h$ (feed) intensifying the cutting forces.

Obviously, one can imagine that tool wear, chipping, and worse sharpness, may increase the thickness of the hardened layer. Respectively, increasing the cutting forces together with an important hardening of the work material could contribute to tool wear. Nonetheless, work material hardening could also be favorable for ductile alloy cutting [16].

\section{Mechanisms Analysis in Orthogonal Cutting}

It is worth noting that the hardened layer analyzed in drilling results from the accumulation of the hardening generated by the successive passage of cutting edges. As a consequence, in such 

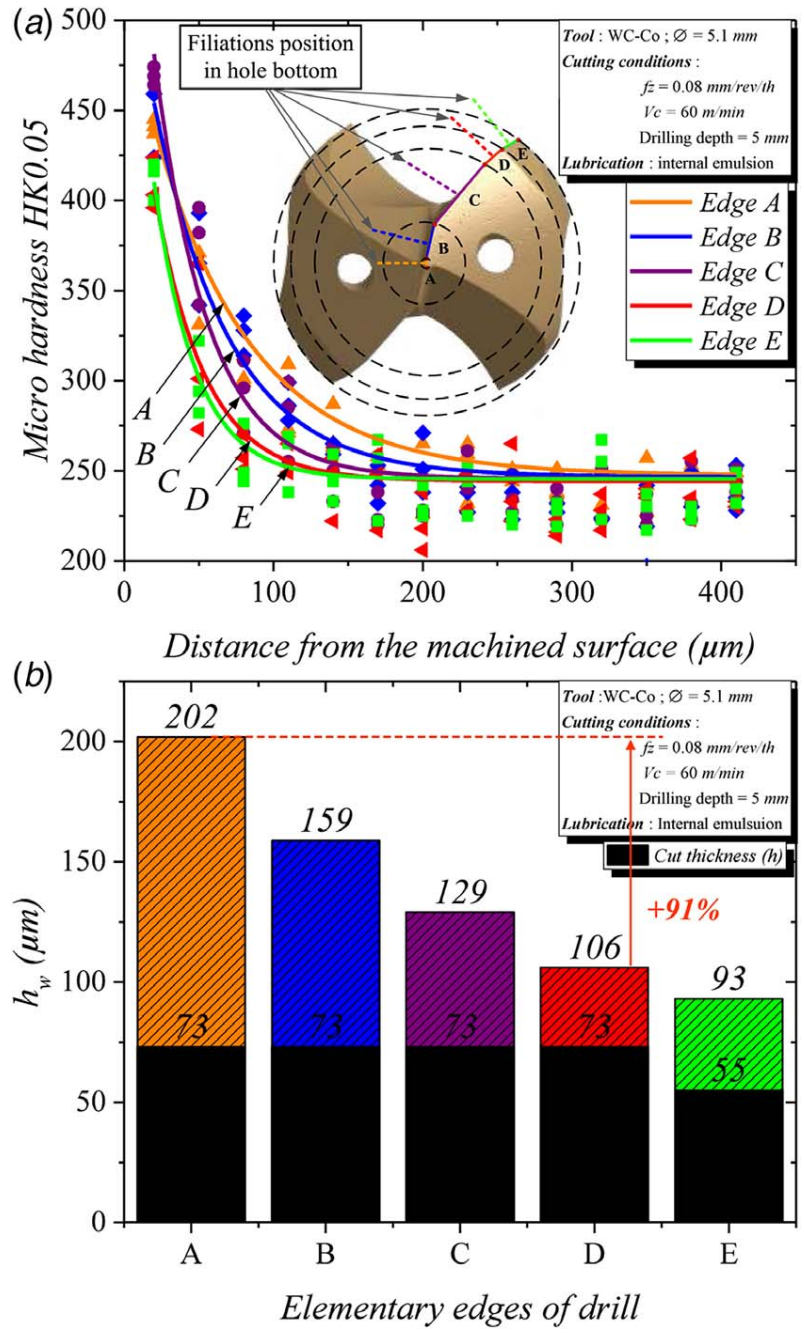

Fig. 7 Effect of the rake angle $\gamma_{n}$ on the hardening depth on the bottom hole: $V_{c}=60 \mathrm{~m} / \mathrm{min}$ and $f_{z}=0.08 \mathrm{~mm} / \mathrm{rev} / \mathrm{th}$

experimental configuration, it is difficult or impossible to individually quantify the contribution of each pass of the cutting edges on the hardened layer formation. To analyze the cumulative effect of the strain hardening under successive passes of the cutting edge, planing tests (orthogonal cutting) equipped with a high-speed camera were carried out. Using the DIC approach to observe and quantify the strains evolution and compare them with hardening characterized by micro hardness enables to assess deeply the work material hardening for each cutting pass. This last being impossible with the QST or any other experimental device directly.

3.1 Experimental Setup. The planing tests are carried out along the $X$-axis of the DMC $85 \mathrm{VL}$ milling machine equipped with linear motors having a maximum speed of $120 \mathrm{~m} / \mathrm{min}$. A Kistler 9119AA2 piezoelectric dynamometer is used to measure the cutting force and the penetration force, respectively, noted $F_{c}$ and $F_{p}$. In parallel, a high-speed camera Photron Fastcam SA-Z is also used to record images of the samples' lateral face during the cutting tool pass at 30,000 fps. In the same manner as Ref. [13], the different measurements are synchronized with the tool displacement. When the tool reaches a programmed position, the acquisition of the different signals connected to the acquisition cards and to the camera is triggered. For the sake of brevity, the experimental setup is not presented here since it had been extensively exposed in several studies already published and considering that it had been used in the exact same way (same signals recorder, camera, and data acquisition synchronization) [17].
Table 3 Tool properties and cutting conditions

\begin{tabular}{ll}
\hline \hline Parameter & \multicolumn{1}{c}{ Value } \\
\hline Tool material & WC-Co \\
Rake angle $\gamma_{n}$ & $7 \mathrm{deg}$ \\
Clearance angle $\alpha$ & $7 \mathrm{deg}$ \\
Edge radius $r_{\beta}$ & $3 \mu \mathrm{m}$ \\
Cut thickness $h$ & $20,40,60,80 \mu \mathrm{m}$ \\
Cutting speed $V_{c}$ & $53 \mathrm{~m} / \mathrm{min}$ \\
Width of cut $b$ & $2.5 \mathrm{~mm}$ \\
\hline
\end{tabular}

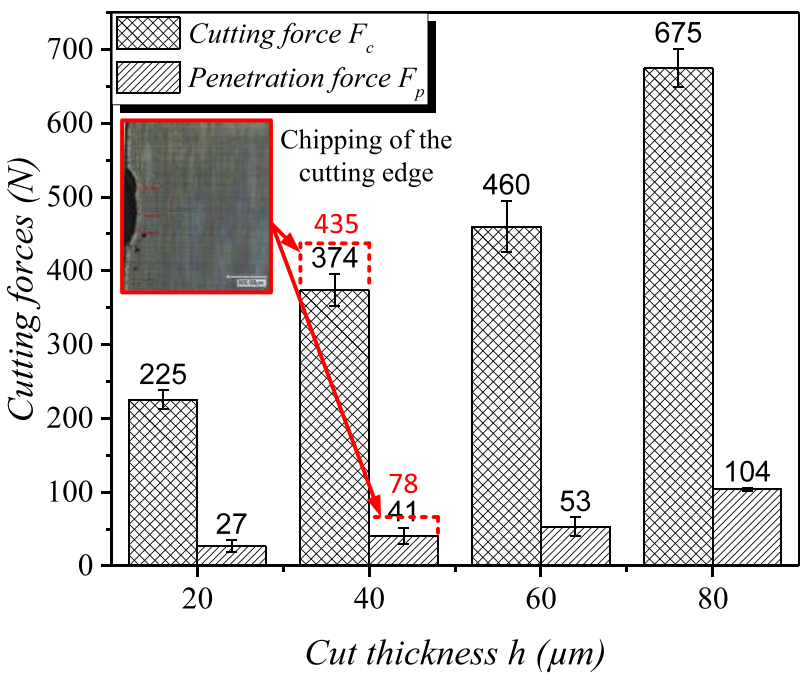

Fig. 8 Evolution of the cutting forces $F_{c}$ and $F_{p}$ according to the cut thickness at $V_{c}=53 \mathrm{~m} / \mathrm{min}$

3.2 Cutting Conditions and Tool Geometry. A unique cutting geometry is used during those planing experiments with an uncoated tungsten carbide (WC-Co) insert. An edge inclination angle of $1.5 \mathrm{deg}$ is used to avoid lateral burr formation during tests that could disturb the machined subsurface observation. Four cut thicknesses are used with a fixed linear cutting speed $(53 \mathrm{~m} / \mathrm{min})$. In these experiments, one sample is used for each cut thickness to isolate the effect of each cutting condition. To resume, all cutting parameters are listed in Table 3.

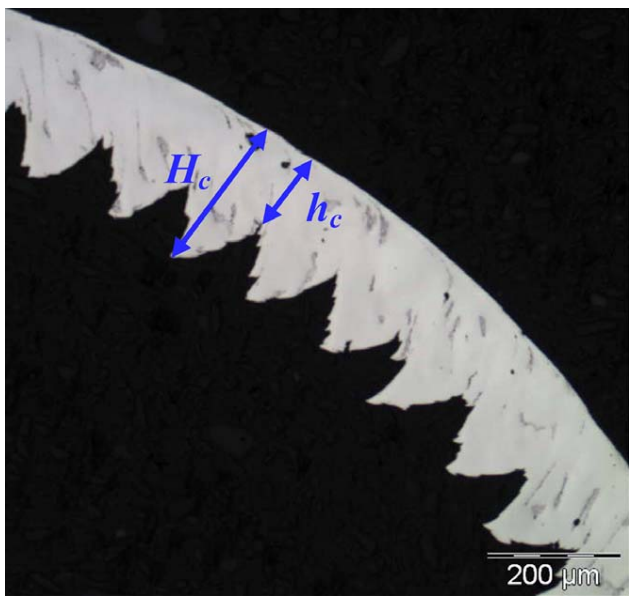

Fig. 9 Micrograph of chip thickness obtained during planing tests: $V_{c}=53 \mathrm{~m} / \mathrm{min}$ and $h=80 \mu \mathrm{m}$ 


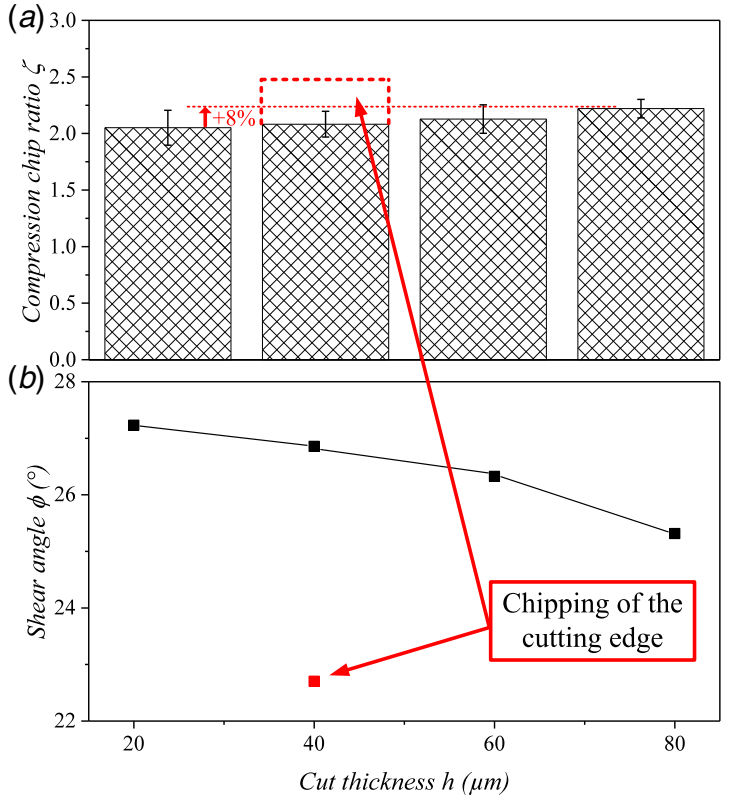

Fig. 10 Effect of the cut thickness $h$ on: (a) the chip compression ratio variation $\xi$ and $(b)$ on the estimated values of the shear angle $\phi-V_{c}=53 \mathrm{~m} / \mathrm{min}$

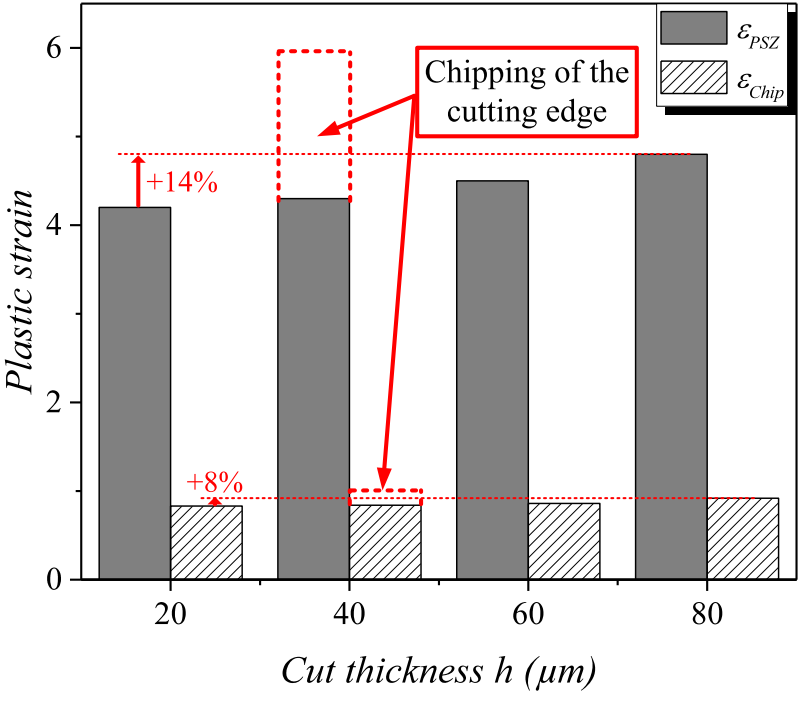

Fig. 11 Estimation of the plastic strain in the PSZ and in the chip $-V_{c}=53 \mathrm{~m} / \mathrm{min}$
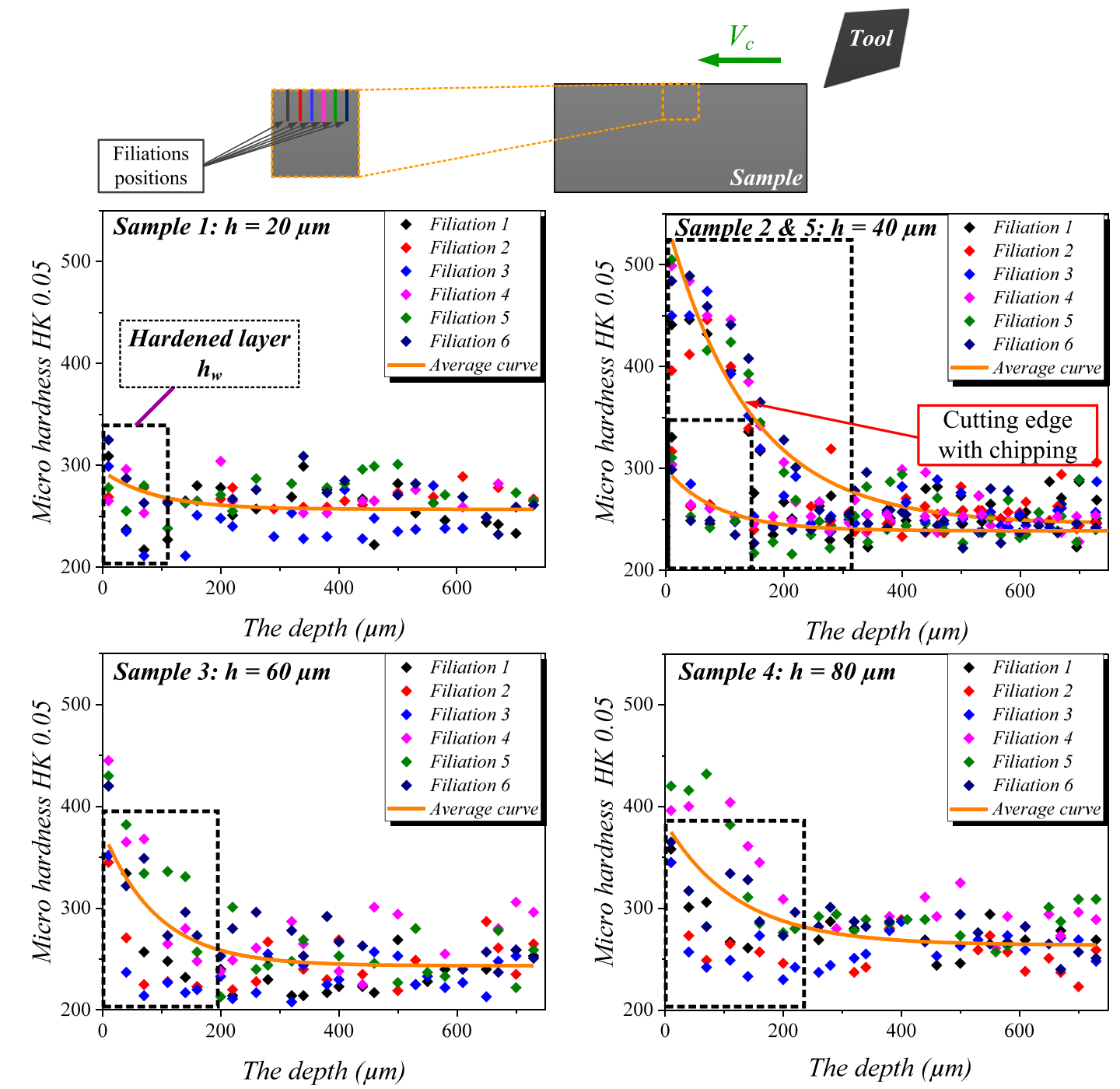

Fig. 12 Micro hardness profiles under the machined subsurfaces for different cut thicknesses $-V_{c}=53 \mathrm{~m} /$ $\min$ and $h=20,40,60$, and $80 \mu \mathrm{m}$ 


\subsection{Results and Analysis}

3.3.1 Cutting Forces Analysis. Figure 8 shows the cutting forces evolution for the four cut thicknesses tested; the error bars presented correspond to the standard deviation obtained from three measurements under the same cutting conditions. According to the results, cutting force $F_{c}$ varies from 225 to $675 \mathrm{~N}$ when $h$ increases from 20 to $80 \mu \mathrm{m}$. The same trend has been observed on the penetration force $F_{p}$; this last rises from 27 to $104 \mathrm{~N}$ with $h$. However, at $h=40 \mu \mathrm{m}$, a chipping on the cutting appeared which may be responsible of the cutting forces increase exhibited with the red dash line on Fig. 8. This cutting condition is repeated with a new tool without chipping. That peculiar test, with a damaged cutting edge, shows once again how the material hardening is very sensitive to the cutting geometry, as it had been shown in Sec. 2.3.2 regarding the rake angle for instance.

3.3.2 Analysis of the Chip Formation. During the orthogonal cutting tests, different chips generated by each cut thickness are analyzed. The results reported are related to their primary parameters (chip thickness ratio and shear angle). In the orthogonal cutting configuration, the chip compression ratio $(\xi)$ is expressed as $\xi=$ $\left(H_{c}+h_{c}\right) / 2 h$ where $H_{c}$ and $h_{c}$ are, respectively, the peak and pinch of the chip (Fig. 9) and $h$ the cut thickness. Generally speaking, $\xi$ represents the mean level of the material deformation during the chip formation process. The variation of $\xi$ according to the different cut thicknesses tested is described in Fig. 10(a). It is found that $\xi$ increases by $8 \%$ when $h$ increases from 20 to $80 \mu \mathrm{m}$. This shows the sensitivity of HRASS machinability with the cut thickness. The shear angle $\phi$ is also calculated based on the $\xi$ values using Eq. (1) where $\gamma_{n}$ is as before the rake angle

$$
\tan \phi=\frac{\cos \gamma_{n}}{\xi-\sin \gamma_{n}}
$$

For the tested range of $h$, the shear angle $\phi$ decreases regularly when $h$ increases as shown in Fig. 10(b). It is also observed that the $\phi$ decreases rapidly with the tool wear (chipping of the cutting edge).

As mentioned previously, M'Saoubi and Chandrasekaran consider $\xi$ as an image of the plastic deformation in orthogonal cutting during metal cutting [18]. Based on the chip compression ratio $\xi$ and the rake angle $\gamma_{n}$ values, Merchant [19] has proposed Eq. (2) to estimate the shear strain in the primary shear zone $\varepsilon_{\mathrm{PSZ}}$. In the same manner, Astakhov and Shvets [20] proposed Eq. (3) to assess the plastic deformation $\varepsilon_{\text {chip }}$ induced in the chip

$$
\begin{gathered}
\varepsilon_{\mathrm{PSZ}}=\frac{\xi^{2}-2 \sin \gamma_{n}+1}{\xi \cos \gamma_{n}} \\
\varepsilon_{\text {chip }}=1.15 \ln \xi
\end{gathered}
$$

According to Fig. $11, \varepsilon_{\mathrm{PSZ}}$ and $\varepsilon_{\text {chip }}$ increase with $h$, respectively, by $14 \%$ and $8 \%$ when $h$ increases from 20 to $80 \mu \mathrm{m}$.

Based on Eqs. (2) and (3), the plastic strain in the chip and in the PSZ could be estimated. So far, the plastic deformation dissipating in the workpiece is not studied yet. So, Sec. 3.3 .3 focuses only on the plastic strain remaining at the subsurface layer.

3.3.3 Characterization of the Hardened Layer of the Machined Subsurface. During orthogonal cutting tests, several passes are realized in order to suppress flatness defects generated during the required polishing preparation. Four samples were used for each cut thickness to isolate the effect of each $h$ values. To ensure the repeatability of the micro hardness measurements, three repetitions have been realized for each $h$ and the same analysis protocol described is Sec. 2 is followed in those specimen cut in orthogonal cutting to determine the depth of the hardened layer generated.

Figure 12 shows the evolution of the micro hardness as a function of the depth from the machined subsurface to the material bulk for the four cut thicknesses tested. The subsurface layers are analyzed after successive tool cut in order to compare as much as possible to the drilling operation (cyclic cutting edge passes on the workpiece without considering the varying cutting geometry along the cutting edge, thermal effects not considered). The continuous curve represents the mean values of the six filiations each containing 20 points of micro hardness with a distance of $40 \mu \mathrm{m}$ between two successive points.

Figures 12 and 13(a) show that the depth of the hardened layer rises with the cut thickness; increasing $h$ from $20 \mu \mathrm{m}$ to $80 \mu \mathrm{m}$, the depth of the hardened layer increases by $135 \mu \mathrm{m}$. As noticed before, during the cutting at $h=40 \mu \mathrm{m}$, having a chipping on the cutting edge (Fig. 8), the depth of the hardened layer has increased substantially by $174 \mu \mathrm{m}$ when compared to the same cut without damaged cutting edge (Fig. 13(a)). Once again, this shows the high sensitivity of strain hardening phenomenon to the tool wear. As observed in drilling, hardened layer thicknesses $h_{w}$ are around three times larger than the set cut thickness $h$, when $h$ passes from 40 to $80 \mu \mathrm{m}$. This ratio reaches five times for $h=20 \mu \mathrm{m}$ explained by an intense ploughing effect linked to a lower $h / r_{\beta}$ ratio. Consequently, the cutting edge always cuts a hardened material for the considered cut thickness in the same way it was for the drilling configuration presented in Sec. 2.3 (QST investigations).

Figure 13(b) presents the area under the curve (integral) and considered as an image of the strain hardening amount generated in the subsurface layer.

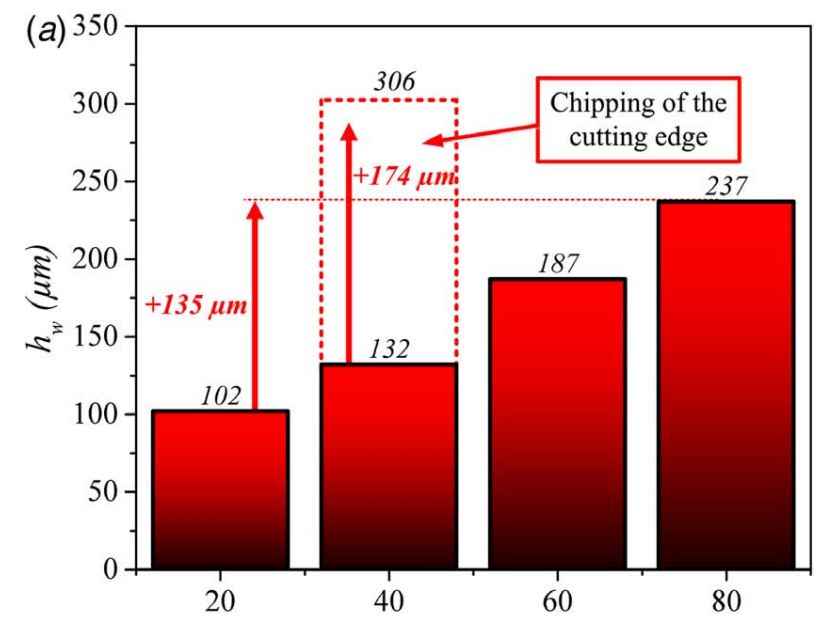

Cut thickness $h(\mu m)$

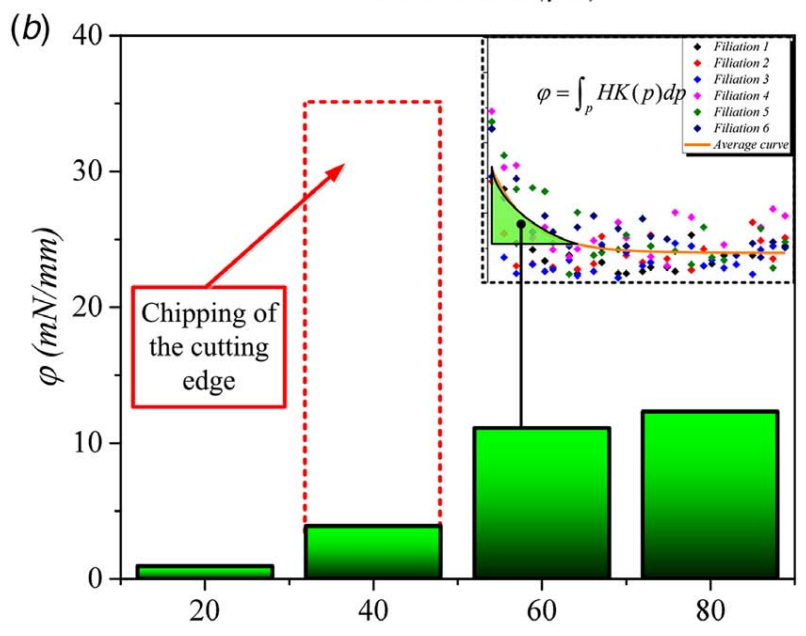

Cut thickness $h(\mu m)$

Fig. 13 Hardened layer thickness $h_{w}$ and its integrals value under subsurface planed samples $-V_{c}=53 \mathrm{~m} / \mathrm{min}$ 
3.3.4 Characterization of the Strain Hardened Layer by Digital Image Correlation During Steady-State. During planing tests, a high-speed camera Photron Fastcam SA-Z, equipped with a Mitutoyo ML $10 \times$ lens, has been used in order to record the tool passes after each cut thickness. The observed area is $1.2 \times$ $1.83 \mathrm{~mm}^{2}$ with a $1024 \times 680$ square pixels resolution, at a frame rate of $30,000 \mathrm{fps}$, a shutter (exposure) time of $1 / 80,000 \mathrm{~s}$, and a dynamic range of 12 bits. That surface resolution of $1.2 \mu \mathrm{m}$ per pixel allows to expect a subpixel displacement measurement accuracy by DIC of around $0.1 \mu \mathrm{m}$ as usually exhibit by the DIC community [21-23]. Previously to machining, the four samples were smoothly sandblasted, with glass micro-beads having diameters of $50-100 \mu \mathrm{m}$, to create a heterogeneous texture required to perform the DIC analysis. The optimal parameters used for that HRASS texturing are $3 \mathrm{~s}$ of exposition time under a pressure of 3 bar to reach the lowest correlation error based on a rigid motion evaluation. For each trial, 201 images have been recorded. Outeiro et al. [24] indicated that the equivalent plastic deformation induced by the cutting process could be calculated between a reference state (the first image was taken before the cut) and the strained state after the cut using the DIC CORRELI ${ }^{\mathrm{Q}}{ }^{2}$ software developed by Besnard et al. [25]. In this analysis, the deformations were not track during the cut, but we are interested the strain hardening remaining on the machined subsurface layer based on the equivalent plastic strain after the elastic springback and after removing the possible rigid body motion. In theory, to deal with equivalent plastic strain, the deformation history should be taken into account. However, the proposed method seems to be still acceptable to compare and analyze the depth of the hardened layer after the cutting process.

Figure 14(a) shows the distribution over the observed surface of the equivalent plastic deformation in the machined subsurface obtained by DIC after $n$ tool passes in order to ensure reaching the steady-state of the deformed layer thickness. Besides, by
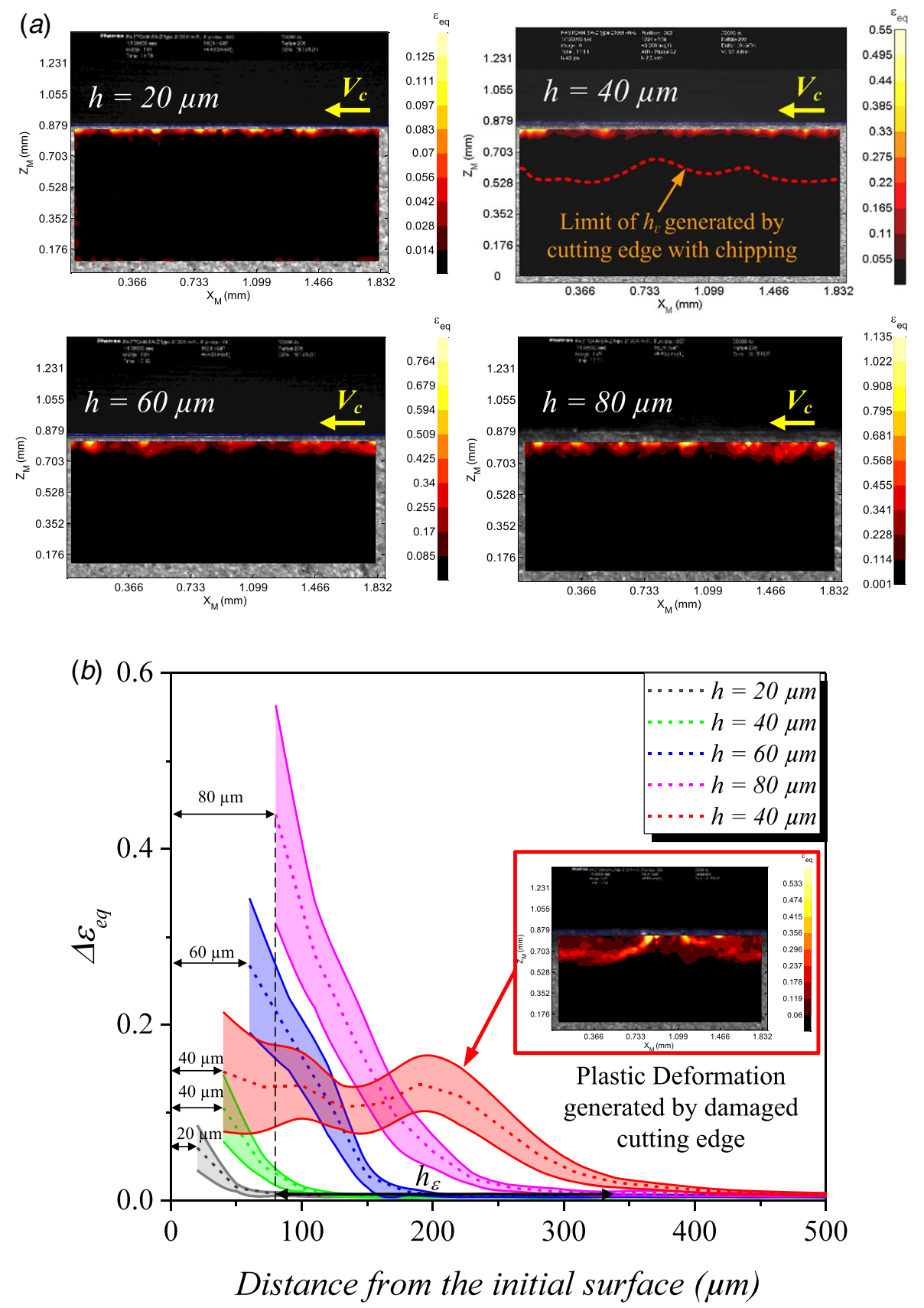

Fig. 14 Evolution of the incremental equivalent plastic deformation $\Delta \varepsilon_{\mathrm{eq}}$ and of the deformed layer thickness $h_{\varepsilon}$ obtained by DIC after $n$ tool passes $-V_{c}=53 \mathrm{~m} / \mathrm{min}$ 
analyzing the displacement field computed between the material states before and after the cut, Fig. 14(b) illustrates the evolution of the incremental equivalent plastic strain $\Delta \varepsilon_{e q}$ generated by each cut thickness and averaged along the observed zone (along the $X$-axis). It needs to be noted that the results are presented on the reference image before the tool passage and that the correlation computation area (Region Of Interest, ROI) had been performed slightly under the machined surface to exclude the immediate subsurface (few $\mu \mathrm{m}$ ) where the correlation errors are too high and where the measurement confidence is too low to be considered as valid.

On Fig. 14(a), envelope curves represent equivalent plastic strains included in one standard deviation. It could be seen that the values of the equivalent plastic strain vary along the observed zone for each cut thickness. This is attributed to the microstructure heterogeneity of the work material which contains dendrites that are 2 times harder than the austenitic matrix.

From these strain fields, it is possible to calculate the depth of the plasticized zone $h_{\varepsilon}$ as displayed in Fig. 14(b) using a threshold at $105 \%$ of the asymptote (corresponding to the bulk material) of each curve. As above mentioned, depending on the cut thickness, the depth of the strain hardened layer varies from $142 \mu \mathrm{m}$ to $256 \mu \mathrm{m}$ and is much higher than the cut thickness itself. In addition, as previously observed by the micro hardness characterization, the strain hardening phenomenon is very sensitive to the tool wear when looking at the $\Delta \varepsilon_{e q}$ field obtained at $h=40 \mu \mathrm{m}$ with a chipped cutting edge; the average strain hardened depth passes from $157 \mu \mathrm{m}$ (for a clear cutting edge) up to $387 \mu \mathrm{m}$ with a damaged edge (cf. Fig. 8).

3.3.5 Cumulative Pass Effect on Strain Hardening. It has been previously stated that the tool cut, either in drilling or planing tests, is influenced by previous cutting passes since the tool always cut a hardened layer induced by the previous tool passes. Thus, the eventual cumulative effect due to successive passes on the evolution of the deformed layer has to be investigated. DIC is the right methodology for such goal and the last five successive passes are analyzed (designated as P03 to P07). Thus, for each analyzed pass, the DIC computes the difference between the strained image (after the elastic springback) and the reference one recorded before all the considered cutting passes. An example is provided for $h=80 \mu \mathrm{m}$ in Fig. $15(a)$ which illustrates the evolution of $\Delta \varepsilon_{e q}$ measured between two successive passes before and after the tool pass. The distributions of the incremental equivalent plastic strain obtained by DIC are presented in Fig. 16. From these strain fields, the depth of the plasticized zone $h_{\varepsilon}$ is calculated as displayed in Fig. 15(b). As observed previously by micro hardness measurements, this analysis also shows that the thickness of the deformed layer $h_{\varepsilon}$ is larger than the cut thickness $h$. Furthermore, these characterizations show that the depth of the deformed layer $h_{\varepsilon}$ increases slowly with the tool pass number to reach a steady-state and consequently demonstrate a deformation accumulation under the cut subsurface. Hence, the deformed layer increases with the number of passes (Fig. 15(b)).

In order to isolate the contribution of each pass on the evolution of strain hardening, the last three passes (P05-P07) are analyzed in Fig. 17. In fact, the area under the curves (integral) of the incremental deformed plastic strain $\Delta \varepsilon_{e q}$ may reflect the participation of each pass on the final strain hardening obtained. The cumulated plastic strain $\varepsilon_{e q-D I C}$ is evaluated by adding the incremental ones $\Delta \varepsilon_{e q}$ caused by the three previous tool passes as described by Eq. (4). Results show that about $84 \%$ of the strain hardening induced during the steady-state cutting is generated by the current pass $P_{i}$, and the remaining $16 \%$ from the previous passes $P_{i-n}$

$$
\varepsilon_{e q-\mathrm{DIC}}=\sum_{i}^{n} \Delta \varepsilon_{e q}\left(P_{i}\right)+\Delta \varepsilon_{e q}\left(P_{i-1}\right)+\Delta \varepsilon_{e q}\left(P_{i-2}\right)
$$

3.3.6 Correlation Between Digital Image Correlation and Micro Hardness Analysis. In order to correlate the DIC and
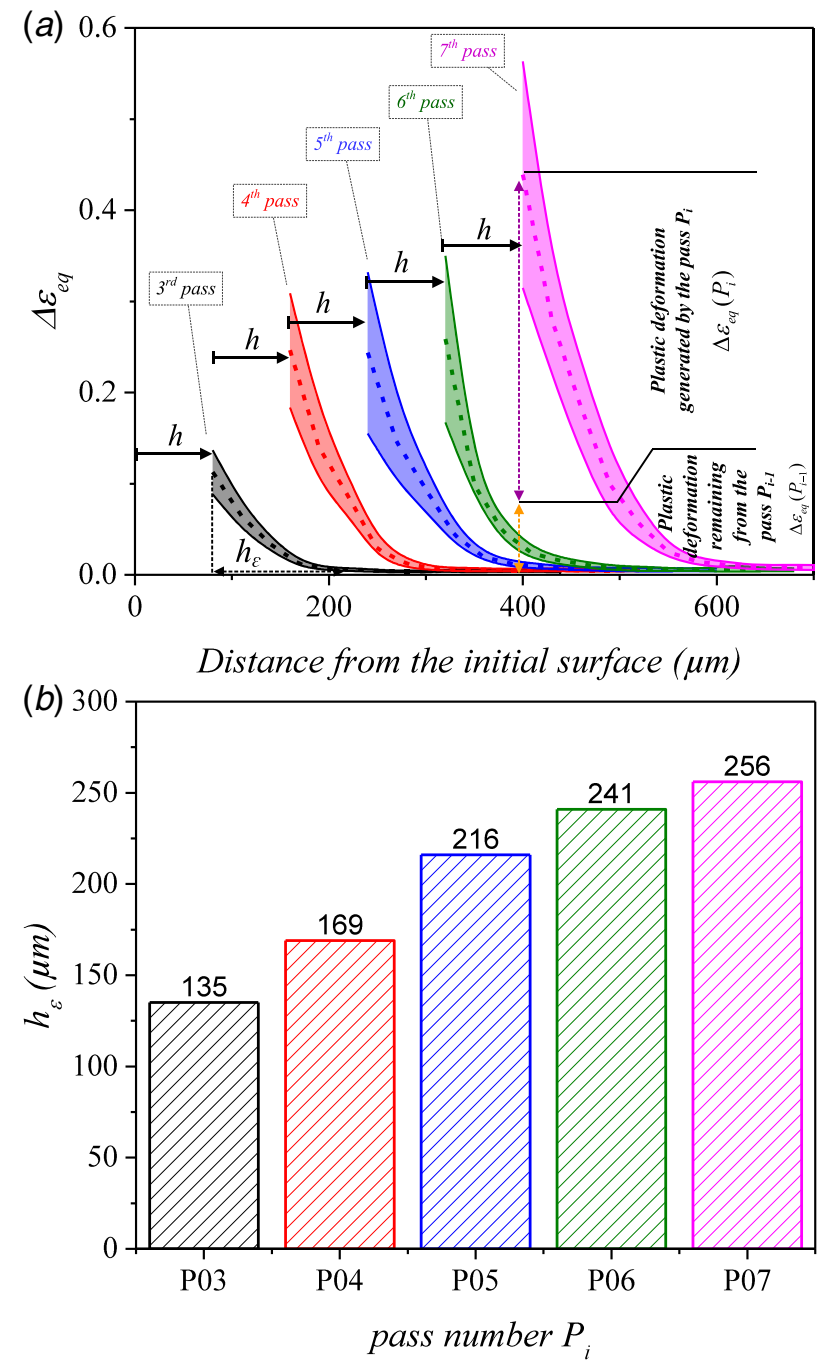

Fig. 15 (a) Evolution of the equivalent plastic strain under successive passes of the cutting edge and (b) effect of the successive passages of the cutting edge on the hardened layer evolution $-V_{c}=53 \mathrm{~m} / \mathrm{min}$ and $h=80 \mu \mathrm{m}$

micro hardness techniques used in this research work to characterize the deformed subsurface layer after the cutting process, two approaches are proposed.

The first approach compares directly the depth of the deformed layer given by the two techniques $\left(h_{w}\right.$ and $\left.h_{\epsilon}\right)$. According to the results illustrated in Fig. 18, the two techniques give similar levels of strain hardening thicknesses showing the robustness of both characterization methodologies.

The second approach is based on plastic strain comparison. It compared indirectly the plastic strain obtained by DIC measurements with the one computed from micro hardness measurements. Firstly, $H K_{0.05}$ values are converted to $H V_{0.05}$, and according to Ref. [26], yield strength could be predicted from micro hardness measurements using Eq. (5)

$$
\sigma_{y}=b+a \times H V
$$

where $a$ and $b$ are the slope and the intercept of the linear approximation proposed by Pavlina and Van Tyne [26] for the austenitic stainless steel, considered as identic to the studied HRASS material, and respectively equal to 2.876 (dimensionless number) and $-90.7 \mathrm{MPa}$. Then, the plastic strain $\varepsilon_{p}$ is predicted based on the Hollomon power law taking into account the strain hardening phenomenon as described in Eq. (6) where $K$ and $n$ are, respectively, 


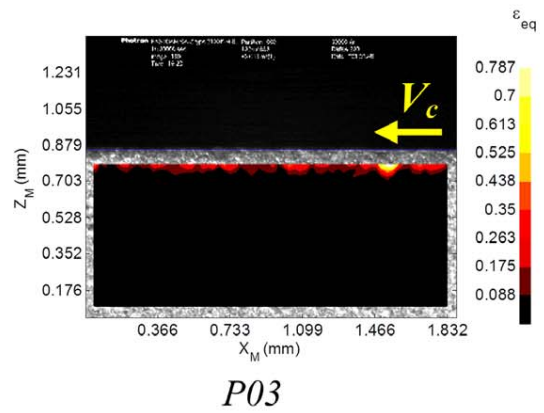

$P 03$

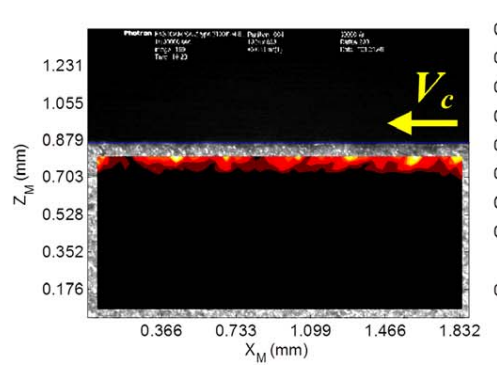

P04
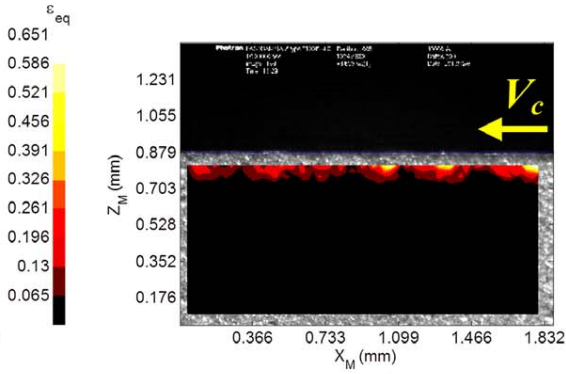

P05

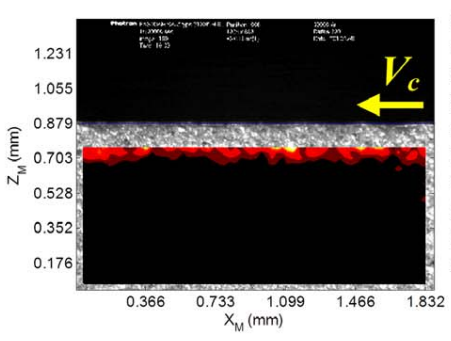

P06

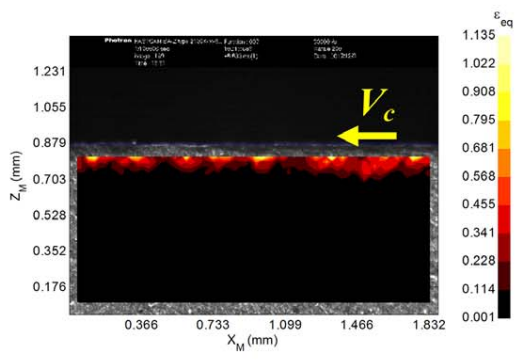

P07

Fig. 16 Distribution of the incremental equivalent plastic strain obtained by DIC, displayed on the reference image

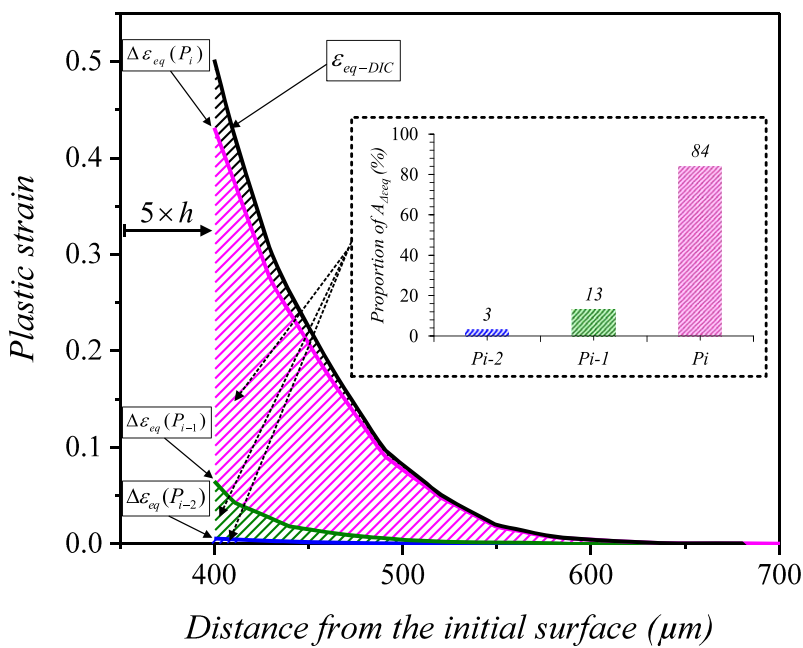

Fig. 17 Contribution of the last three passes (P05-P07) on the evolution of strain hardening $-V_{c}=53 \mathrm{~m} / \mathrm{min}$ and $h=80 \mu \mathrm{m}$

the strength coefficient and the strain hardening exponent

$$
\sigma_{y}=K\left(\varepsilon_{p}\right)^{n} \quad \text { with } \varepsilon_{p}=\left(\varepsilon-\varepsilon_{e}\right)
$$

To determine $K$ and $n$, tensile tests are performed at room temperature and based on the logarithm of the stress according to the logarithm of the plastic strain in the region of uniform elongation; they are, respectively, equal to $943 \mathrm{MPa}$ and 0.19 . From Eqs. (5) and (6), the plastic strain can be expressed as in Eq. (7)

$$
\varepsilon_{e q-H V}=\left(\frac{b+a \times H V}{K}\right)^{1 / n}
$$

The ultimate pass is analyzed by DIC as the plastic strain obtained in the last pass resulting from the accumulated ones generated by the previous passes, while micro hardness measurements are performed only after the last pass. An example of results is given in Fig. 19, showing a comparison of the plastic strain obtained by

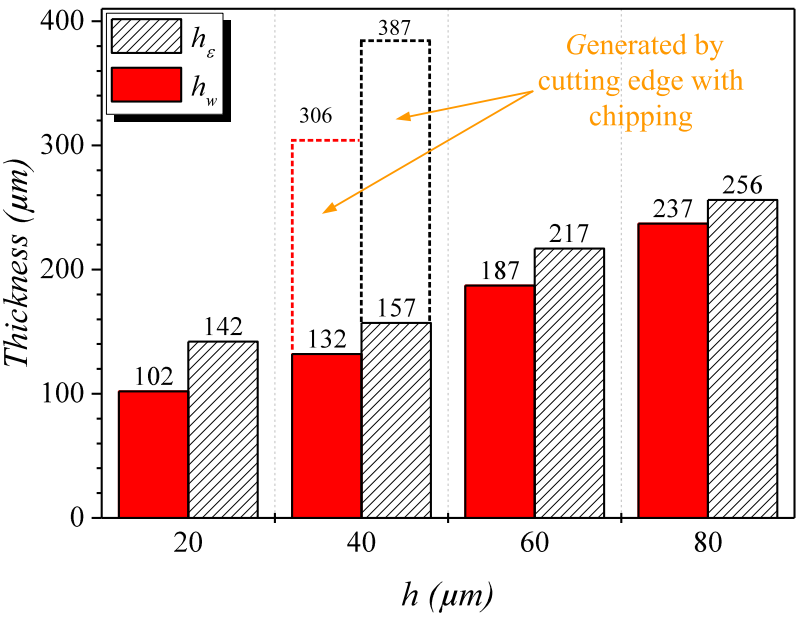

Fig. 18 Comparison of the strained thickness $h_{\varepsilon}$ evaluated by DIC and the hardened thickness $h_{w}$ measured by micro hardness after $n$ tool passes $-V_{c}=53 \mathrm{~m} / \mathrm{min}$

the DIC and the one estimated from micro hardness when cutting at $h=80 \mu \mathrm{m}$ (the other cutting thicknesses provide the same trends but are not shown here for the sake of brevity). According to the results, the two methods show a good agreement. However, the second method underestimates the prediction of the plastic strain, as the micro hardness points are measured at an offset of $15 \mu \mathrm{m}$ from the surface edge analyzed contrary to the DIC method which allows to assess the plastic strain directly from the surface edge without any offset.

In this approach, it should be noticed that the temperature and the strain rate effect are neglected to correlate the micro hardness measurements to the plastic strain computed. The major part of the machining heat is carried away by the chips in metal cutting, and the strain rate effect is usually low compared to the strain hardening. Thus, both are considered as second-order factors when focusing on the surface integrity of the machined layer, moreover one can balance the other. Finally, this approach is proposed to analyze trends and to check the coherence of measurement values of micro hardness and plastic strain determined by DIC. 


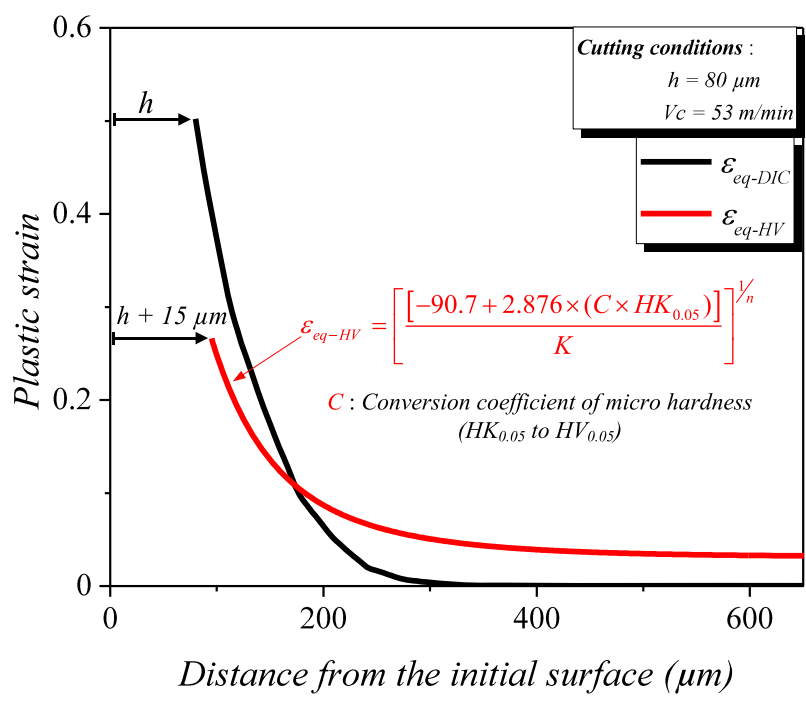

Fig. 19 Comparison of the plastic strain calculated by DIC and predicted from micro hardness measurements after $n$ tool passes $-V_{c}=53 \mathrm{~m} / \mathrm{min}$ and $h=80 \mu \mathrm{m}$

\section{Conclusions}

The current study presents several experimental works to investigate the strain hardening of the subsurface layer created during HRASS machining and the analysis of the cumulative cutting effect.

The machined subsurface has been analyzed using QST in drilling to assess not only the effect of the cutting conditions but also the effect of the local cutting geometry on the cumulative strain hardening linked to multi-edge cuts. Micro hardness has been chosen to estimate the influence of the cutting conditions $\left(f_{z}\right.$ and $\left.V_{c}\right)$ and the local rake angle $\gamma_{n}$ variation along the main cutting edge on the strain hardened layer depth. To resume, extensive cutting conditions of HRASS increase the thickness of the strain hardened layer. Furthermore, this last rises from the drill corner to the drill center; strain hardening increases when the rake angle becomes negative. Furthermore, the hardened thickness is at least twice to more than three times larger than the cut thickness depending on the effective rake angle and cut thickness. As a consequence, during drilling of HRASS, the cutting edges permanently cut the strain hardened layer remnants from the previous cut.

In orthogonal cutting, the cumulative effect of the strain hardening generated by successive tool passes has also been characterized by DIC based on the incremental plastic strain identification. Results have shown that the major part (84\%) of strain hardening induced during the steady-state cutting process is generated by the current pass $P_{i}$, while the rest $(16 \%)$ is remaining from the previous passes $P_{i-n}$. Nevertheless, the hardened layer thickness is three times higher than the cut thickness for the same condition ( $h=80 \mu \mathrm{m}$ ) when steady-state is reached (after five passes). Additionally, it is found that the tool wear increases expressively the thickness of the strain hardened layer. Finally, results of micro hardness measurements, with those of DIC are compared in terms of the depth of the deformed subsurface layer and its hardness too; both approaches are concordant.

These investigations have shown that the strain hardening could not be neglected during the machining of HRASS. This phenomenon may increase the cutting forces especially in the drilling process as the depth of the strain hardened layer is larger than the cut thickness: the tool always cut a hardened material. The studied work material contains hard carbides but is also initially ductile and sticky due to its austenitic matrix. Correspondingly, its hardening could ease any cutting process of such material even if not presently established. V. P. Astakhov, in J. P. Davim book, proposed advanced plastic deformation of ductile materials to enhance their machinability [16].

\section{Acknowledgment}

Financial support of our work by Saint Jean Tooling Company and the help of Saint Jean Lorraine are gratefully acknowledged. The authors would like to thank specially Patrick Blandenet, Véronique Bouvier, Gérald Jonnery, Jérémy Morgon, Jean-Baptiste Fayard, and Jonathan Malik for their guidance and technical supports. We would like also to thank ENI from Saint-Etienne for their technical support with QSD in drilling.

\section{References}

[1] Diniz, A. E., Machado, Á. R, and Corrêa, J. G., 2016, "Tool Wear Mechanisms in the Machining of Steels and Stainless Steels," Int. J. Adv. Manuf. Technol., 87(9-12), pp. 3157-3168

[2] Routio, M., and Säynätjoki, M., 1995, "Tool Wear and Failure in the Drilling of Stainless Steel," J. Mater. Process. Technol., 52(1), pp. 35-43.

[3] Sultan, A. Z., Sharif, S., and Kurniawan, D., 2015, "Effect of Machining Parameters on Tool Wear and Hole Quality of AISI 316L Stainless Steel in Conventional Drilling," Procedia Manuf., 2, pp. 202-207.

[4] Dolinšek, S., 2003, "Work-Hardening in the Drilling of Austenitic Stainless Steels," J. Mater. Process. Technol., 133(1-2), pp. 63-70.

[5] Jiang, L., Roos, ̊̊, and Liu, P., 1997, "The Influence of Austenite Grain Size and Its Distribution on Chip Deformation and Tool Life During Machining of AISI 304L," Metall. Mater. Trans. A, 28(11), pp. 2415-2422.

[6] Krolczyk, G., Legutko, S., and Stoić, A., 2013, "Influence of Cutting Parameters and Conditions Onto Surface Hardness of Duplex Stainless Steel After Turning Process," Teh. Vjesn., 20(6), pp. 1077-1080.

[7] Chern, G.-L., 2005, "Development of a New and Simple Quick-Stop Device for the Study on Chip Formation,” Int. J. Mach. Tools Manuf., 45(7), pp. 789-794.

[8] Ozturk, S., and Altan, E., 2012, "Design of a Computer Aided Quick-Stop Device for Study of Dead Metal Zone Formation," J. Braz. Soc. Mech. Sci. Eng., 34(4), pp. 501-505.

[9] Davis, B., Dabrow, D., Ifju, P., Xiao, G., Liang, S. Y., and Huang, Y., 2018, "Study of the Shear Strain and Shear Strain Rate Progression During Titanium Machining," ASME J. Manuf. Sci. Eng., 140(5), p. 051007.

[10] Zhang, D., Zhang, X.-M., and Ding, H., 2018, "Hybrid Digital Image Correlation-Finite Element Modeling Approach for Modeling of Orthogonal Cutting Process," ASME J. Manuf. Sci. Eng., 140(4), p. 041018.

[11] Baizeau, T., Rossi, F., Poulachon, G., and Outeiro, J. C., 2016, "Prediction of Surface Integrity Using Flamant-Boussinesq Analytical Model," CIRP Ann., 65(1), pp. 81-84

[12] Baizeau, T., Campocasso, S., Fromentin, G., Rossi, F., and Poulachon, G., 2015, "Effect of Rake Angle on Strain Field During Orthogonal Cutting of Hardened Steel With c-BN Tools," Procedia CIRP, 31, pp. 166-171.

[13] Baizeau, T., Campocasso, S., Rossi, F., Poulachon, G., and Hild, F., 2016, "Cutting Force Sensor Based on Digital Image Correlation for Segmented Chip Formation Analysis," J. Mater. Process. Technol., 238, pp. 466-473.

[14] Arif, R., Fromentin, G., Rossi, F., and Marcon, B., 2019, "Mechanical Analysis of Local Cutting Forces and Transient State When Drilling of Heat-Resistant Austenitic Stainless Steel,” Int. J. Adv. Manuf. Technol., 104, pp. 2247-2258.

[15] Claudin, C., 2006, "Influence des Conditions Opératoires sur le Procédé de Perçage: Application aux Structures Mécano-Soudées en Acier bas Carbone," $\mathrm{Ph} . \mathrm{D}$. thesis, ENSAM, Paris.

[16] Davim, J. P., 2014, Machinability of Advanced Materials, John Wiley \& Sons Incorporated, Hoboken, NJ.

[17] Régnier, T., Marcon, B., Outeiro, J., Fromentin, G., D’Acunto, A., and Crolet, A., 2019, "Investigations on Exit Burr Formation Mechanisms Based on Digital Image Correlation and Numerical Modeling," Mach. Sci. Technol., 23(6), pp. 925-950.

[18] M'Saoubi, R., and Chandrasekaran, H., 2004, "Role of Phase and Grain Size on Chip Formation and Material Work Hardening During Machining of Single and Dual Phase Steels," Ironmaking Steelmaking, 31(3), pp. 258-264.

[19] Merchant, M. E., 1945, "Mechanics of the Metal Cutting Process. I. Orthogonal Cutting and a Type 2 Chip," J. Appl. Phys., 16(5), pp. 267-275.

[20] Astakhov, V. P., and Shvets, S., 2004, "The Assessment of Plastic Deformation in Metal Cutting," J. Mater. Process. Technol., 146(2), pp. 193-202.

[21] Dupré, J.-C., Bornert, M., Robert, L., and Wattrisse, B., 2010, "Digital Image Correlation: Displacement Accuracy Estimation," EPJ Web Conf, 6, p. 31006.

[22] Hild, F., and Roux, S., 2006, "Digital Image Correlation: From Displacement Measurement to Identification of Elastic Properties-A Review," Strain, 42(2), pp. 69-80.

[23] Roux, S., Hild, F., and Berthaud, Y., 2002, "Correlation Image Velocimetry: A Spectral Approach," Appl. Opt., 41(1), pp. 108-115.

[24] Outeiro, J., Campocasso, S., Denguir, L., Fromentin, G., Vignal, V., and Poulachon, G., 2015, "Experimental and Numerical Assessment of Subsurface Plastic Deformation Induced by OFHC Copper Machining," CIRP Ann., 64(1), pp. 53-56.

[25] Besnard, G., Hild, F., and Roux, S., 2006, "'Finite-Element' Displacement Fields Analysis From Digital Images: Application to Portevin-Le Châtelier Bands," Exp. Mech., 46(6), pp. 789-803.

[26] Pavlina, E. J., and Van Tyne, C. J., 2008, "Correlation of Yield Strength and Tensile Strength With Hardness for Steels," J. Mater. Eng. Perform., 17(6), pp. $888-893$. 